\title{
Unique Contribution of Haptoglobin and Haptoglobin Genotype in Aneurysmal Subarachnoid Hemorrhage
}

\begin{abstract}
Spiros L. Blackburn ${ }^{1 *}$, Peeyush T. Kumar ${ }^{1}$, Devin McBride ${ }^{1}$, Hussein A. Zeineddine ${ }^{1}$, Jenna Leclerc ${ }^{2}$, H. Alex Choi ${ }^{1}$, Pramod K. Dash ${ }^{1}$, James Grotta ${ }^{3}$, Jaroslaw Aronowski ${ }^{3}$, Jessica C. Cardenas ${ }^{4}$ and Sylvain Dorée 2,5

${ }^{1}$ Department of Neurosurgery, The University of Texas Houston Health Sciences Center, Houston, TX, United States, ${ }^{2}$ Department of Anesthesiology, University of Florida, College of Medicine, Gainesville, FL, United States, ${ }^{3}$ Department of Neurology, The University of Texas Health Sciences Center, Houston, TX, United States, ${ }^{4}$ Department of Surgery, Division of Acute Care Surgery and Center for Translational Injury Research, The University of Texas Health Science Center, Houston, TX, United States, ${ }^{5}$ Departments of Neurology, Psychiatry, Psychology, Pharmaceutics, and Neuroscience, University of Florida, McKnight Brain Institute, Gainesville, FL, United States
\end{abstract}

OPEN ACCESS

Edited by:

John D. Imig,

Medical College of Wisconsin

United States

Reviewed by:

Selva Baltan,

Cleveland Clinic Lerner College of

Medicine, United States

Emanuela Tolosano,

Università degli Studi di Torino, Italy

*Correspondence:

Spiros L. Blackburn

spiros.blackburn@uth.tmc.edu

Specialty section:

This article was submitted to

Vascular Physiology,

a section of the journal

Frontiers in Physiology

Received: 06 February 2018 Accepted: 02 May 2018

Published: 31 May 2018

Citation:

Blackburn SL, Kumar PT, McBride D,

Zeineddine HA, Leclerc J, Choi HA,

Dash PK, Grotta J, Aronowski J,

Cardenas JC and Doré S (2018)

Unique Contribution of Haptoglobin

and Haptoglobin Genotype in

Aneurysmal Subarachnoid

Hemorrhage. Front. Physiol. 9:592.

doi: 10.3389/fphys.2018.00592
Survivors of cerebral aneurysm rupture are at risk for significant morbidity and neurological deficits. Much of this is related to the effects of blood in the subarachnoid space which induces an inflammatory cascade with numerous downstream consequences. Recent clinical trials have not been able to reduce the toxic effects of free hemoglobin or improve clinical outcome. One reason for this may be the inability to identify patients at high risk for neurologic decline. Recently, haptoglobin genotype has been identified as a pertinent factor in diabetes, sickle cell, and cardiovascular disease, with the Hp 2-2 genotype contributing to increased complications. Haptoglobin is a protein synthesized by the liver that binds free hemoglobin following red blood cell lysis, and in doing so, prevents hemoglobin induced toxicity and facilitates clearance. Clinical studies in patients with subarachnoid hemorrhage indicate that $\mathrm{Hp} \mathrm{2-2} \mathrm{patients} \mathrm{may} \mathrm{be} \mathrm{a} \mathrm{high-risk} \mathrm{group} \mathrm{for} \mathrm{hemorrhage}$ related complications and poor outcome. We review the relevance of haptoglobin in subarachnoid hemorrhage and discuss the effects of genotype and expression levels on the known mechanisms of early brain injury (EBI) and cerebral ischemia after aneurysm rupture. A better understanding of haptoglobin and its role in preventing hemoglobin related toxicity should lead to novel therapeutic avenues.

Keywords: cerebral vasospasm, genetic biomarker, heme, microthrombosis, neuroinflammation, personalized medicine, prognostic marker, subarachnoid hemorrhage

\section{INTRODUCTION}

Aneurysmal subarachnoid hemorrhage (aSAH) affects more than 30,000 people per year in the United States, with an estimated 30-50\% mortality (Hop et al., 1997; Stegmayr et al., 2004; Zacharia et al., 2010). It is the deadliest form of stroke. Although the initial hemorrhage and early brain injury (EBI) is a major cause of poor outcomes, delayed mechanisms of brain injury also play a significant role. 
Cerebral vasospasm (CV) and delayed cerebral infarcts (DCI) are the most studied delayed events and are known to contribute to poor outcomes after aSAH (Rosengart et al., 2007). Nevertheless, extensive basic research and clinical trials targeting CV have not delivered significant progress likely due to the fact that cerebral ischemia also occurs in regions without clear angiographic vasospasm (Gomis et al., 2010; Macdonald et al., 2011). Furthermore, CV is only one mechanism contributing to poor outcomes in addition to inflammation, cerebral microthrombosis, blood brain barrier (BBB) dysfunction and cortical spreading depolarizations (Neil-Dwyer et al., 1994; Stein et al., 2006; Vergouwen et al., 2008; Dreier et al., 2009; Dhar et al., 2012; Woitzik et al., 2012). As the cerebral injury is largely multifactorial, targeting one aspect may have limited efficacy in reducing delayed brain injury.

Following aneurysmal rupture, a transient increase in intracranial pressure and a decrease in cerebral blood flow result in the initiation of an EBI cascade that includes global cerebral ischemia and cerebral edema (Bederson et al., 1995; Claassen et al., 2002; Schubert et al., 2011). Much of the evidence for this comes from animal studies rather than clinical studies due to the inability to monitor the ictus, and is reviewed elsewhere (Sehba et al., 2012; Sabri et al., 2013b). In animal models, this cascade results in inflammation, endothelial cell necrosis/apoptosis, neuronal apoptosis, and autoregulatory dysfunction and remains a critical area of active research.

With this EBI, blood is released into the subarachnoid space, mixing with cerebrospinal fluid (CSF), and forming a clot. Within $24 \mathrm{~h}$ following aSAH, an intense polymorphonuclear leukocyte infiltration of the meninges is seen (Macdonald and Weir, 1991). Phagocytosis (targeting hematoma clearance) and lysis of red blood cells (RBCs) occurs by $16-32 \mathrm{~h}$, but continues for days, with clumps of intact RBCs still enmeshed in the arachnoid for up to 35 days after aSAH (Macdonald and Weir, 1991; Foreman, 2016). It is estimated that $>250$ million molecules of hemoglobin $(\mathrm{Hb})$ are released per single $\mathrm{RBC}$ (Wintrobe and Greer, 2004). The inert free Hb, unless bound by its high affinity binding protein haptoglobin $(\mathrm{Hp})$ will quickly undergo oxidation and become a potent pro-inflammatory and cytotoxic molecule (Foley et al., 1994; Ascenzi et al., 2005). In binding with Hb, Hp prevents oxidation and thus confers a neuroprotective role (Zhao et al., 2009; Andersen et al., 2012).

In humans, there are two alleles for $\mathrm{Hp}$, and a number of known rare variants (Langlois and Delanghe, 1996). The role of Hp genotype and its relevance to disease severity has been studied in different specialties including epilepsy, cardiovascular disease, diabetes, sickle cell, and renal disease (Panter et al., 1985; Langlois and Delanghe, 1996; Asleh et al., 2003; Sadrzadeh et al., 2004; Amiri et al., 2013; MacKellar and Vigerust, 2016). The overall conclusion of these studies is that the Hp2-2 genotype is associated with a more severe disease phenotype, and with increased immune reactivity (Langlois and Delanghe, 1996; Roguin et al., 2003; Levy et al., 2007, 2010; Goldenstein et al., 2012; Purushothaman et al., 2012).

Three previous studies have demonstrated a link between $\mathrm{Hp}$ genotype and incidence of CV following aSAH (Borsody et al., 2006; Ohnishi et al., 2013; Leclerc et al., 2015). In a fourth study (the largest study with 193 patients), Kantor et al. identified Hp2-2 as a predictor of poor outcomes but did not evaluate DCI or cerebral vasospasm (Kantor et al., 2014). The association between poor outcome and $\mathrm{Hp}$ 2-2 has been reproduced in one study, though contested in another (Ohnishi et al., 2013; Leclerc et al., 2015). Taken as a whole, this data implicates Hp genotype has the potential to be an important mediator in long term patient outcome after aSAH. In this review, we discuss the role that $\mathrm{Hp}$ and $\mathrm{Hp}$ polymorphism plays, and how this influences the mechanisms of delayed injury following aSAH along with supporting evidence. Understanding the role of $\mathrm{Hp}$ on the clearance of hemoglobin from the CSF and brain, and its mitigation of pathological mediators after aSAH may lead to novel therapeutics.

\section{EXTRACELLULAR HEMOGLOBIN PROCESSING AND THE ROLE OF HAPTOGLOBIN}

Under normal conditions, $\mathrm{Hb}$ is confined to the $\mathrm{RBC}$, and intracellular $\mathrm{Hb}$ undergoes auto-oxidation at a slow rate, producing methemoglobin (metHb) and reactive oxygen species (ROS), primarily superoxide anion (Shikama, 1998; Boutaud et al., 2010). However, an extensive antioxidant system within the $\mathrm{RBCs}$ is responsible for reducing the oxidized $\mathrm{Hb}$ and neutralizing the ROS (Gonzales et al., 1984; Lee et al., 2003; Nagababu et al., 2003) (Figure 1).

Extracellular $\mathrm{Hb}$ (i.e., after RBC lysis) will undergo a series of oxidative reactions generating metHb, which undergoes further oxidation producing free heme and free iron (Rifkind et al., 2014). Considering that 250-270 million molecules of $\mathrm{Hb}$ are released per $\mathrm{RBC}$, and that each $\mathrm{Hb}$ contains four hemes (also called iron-protoporphyrin IX), RBC lysis quickly creates levels of $\mathrm{Hb}$ that the brain cells cannot efficiently metabolize. These $\mathrm{Hb}$ molecules are the source of pathological reactions including production of free radicals, induction of proinflammatory cascades, endothelial and smooth muscle cell dysfunction and injury, and reduced NO availability (Sadrzadeh et al., 1984; Touyz and Schiffrin, 2004; Figueiredo et al., 2007; Azarov et al., 2008; Silva et al., 2009; Cabrales and Friedman, 2013; Lisk et al., 2013). Iron imparts significant cell damage and neuronal death following aSAH, though some argue that the iron binding protein ferritin could be sufficient to mitigate iron-toxicity. Deleterious effects of iron were suggested to be reduced in rat SAH models treated with the iron chelator, deferoxamine (Lee et al., 2010). However, toxicity related to clinical use of deferoxamine would limit its use.

Haptoglobin is an acute phase reactant primarily produced by the liver and is the major $\mathrm{Hb}$ binding plasma protein. Formation of $\mathrm{Hp}-\mathrm{Hb}$ complex mediates clearance of $\mathrm{Hb}$ by internalization of this complex through scavenger membrane receptor CD163 on monocytes and macrophages in the liver and spleen, and potentially microglia within the brain in case of cerebral bleeding (Schaer C. A. et al., 2013; Schaer D. J. et al., 2013; Rifkind et al., 2014; Schaer et al., 2014). Once internalized, the heme is degraded by heme oxygenase 1 (HO1) into biliverdin and iron (Thomsen 


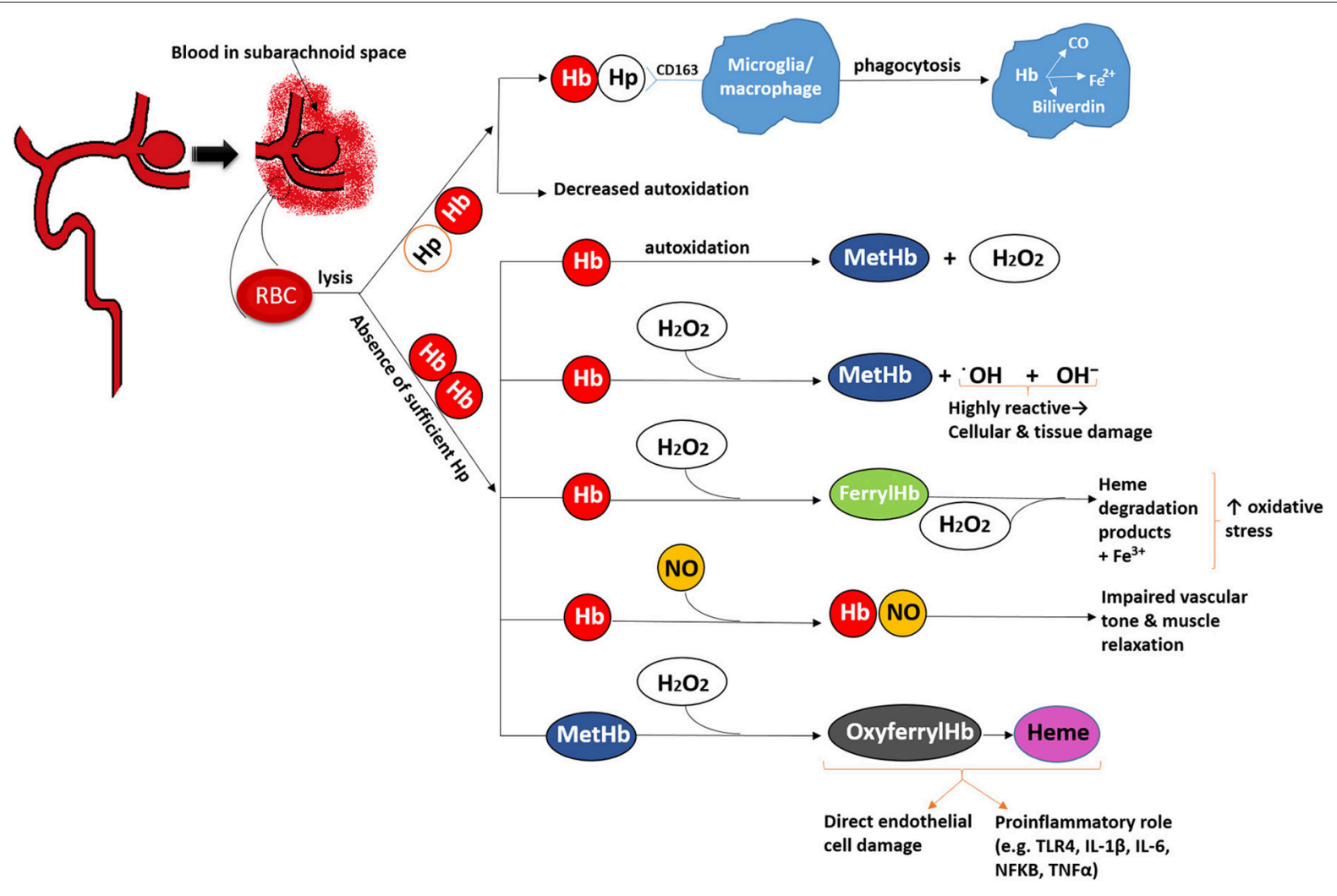

FIGURE 1 | Overall representation of the role of haptoglobin.

et al., 2013). The HO1 is induced by heme as well as inflammatory cytokines (Terry et al., 1998; Thomsen et al., 2013).

In the absence of sufficient $\mathrm{Hp}$ reserve (e.g., hypohaptoglobinemia), $\mathrm{Hb}$ structure is often modified by the oxidation which reduces ability of CD163 to bind the complex (Vallelian et al., 2008). Hp-Hb binding stabilizes the $\mathrm{Hb}$ structure, prevents $\mathrm{Hb}$ protein oxidation, and preserves CD163 binding such that the $\mathrm{Hb}$ can be effectively endocytosed by the phagocyte, and then metabolized by heme oxygenase (Buehler et al., 2009). The protective mechanisms of $\mathrm{Hp}$ are particularly relevant in the intravascular space where hemolysis often occur. However, $\mathrm{Hp}$ although present in the CSF, is not as abundant as in the blood and is readily overwhelmed by the molar ratio of $\mathrm{Hb}$ after $\mathrm{SAH}$ (Galea et al., 2012). Presumably, this facilitates heme-iron induced oxidative stress and an exuberant pro-inflammatory cascade with consequences including vascular injury, cerebral vasospasm, microthrombosis, and neuronal toxicity. In intracerebral hemorrhage (ICH) models, experimentally-induced hypohaptoglobimemia resulted in increased oxidative stress in the peri-hematoma tissue, while animals overexpressing human $\mathrm{Hp}$ demonstrated less neurological damage and less injury to the neurons and oligodendroglia within the ICH-affected brain (Zhao et al., 2009).

Two major alleles, $\mathrm{Hp} 1$ and $\mathrm{Hp} 2$, exist for the $\mathrm{Hp}$ gene found on chromosome 16. The two alleles are responsible for three different possible genotypes with structural polymorphism: homozygous (1-1 or 2-2) and heterozygous 2-1. In Western populations, it is estimated that the distribution of $\mathrm{Hp} \mathrm{1-1} \mathrm{is}$ $\sim 16 \%$, Hp $2-1$ is $\sim 48 \%$, and $\mathrm{Hp} 2-2$ is $\sim 36 \%$. Hp is cleaved into two subunits $\alpha$ and $\beta$ chains, joined by a disulfide bond. Both alleles share the same $\beta$ chain (Goldenstein et al., 2012). The $\beta$ chain is responsible for binding the $\mathrm{Hb}$, thus both genotypes have similar $\mathrm{Hb}$ binding affinity (Asleh et al., 2005). However, the $\mathrm{Hp}-\mathrm{Hb}$ complex formed with $\mathrm{Hp} 1-1$ is a superior antioxidant compared to Hp 2-2, and Hp 1-1 patients have higher circulating Hp levels (Langlois and Delanghe, 1996; Melamed-Frank et al., 2001; Dalan et al., 2016, 2017). In addition, the circulating Hp11 bound hemoglobin is cleared faster than its Hp 2 counterpart (Asleh et al., 2003; Azarov et al., 2008).

\section{NEUROINFLAMMATION}

Neuroinflammation ensues following aSAH with increased chemokines and cytokines in CSF and serum. Certain cytokines, specifically IL- $1 \beta, \mathrm{TNF} \alpha$, and IL- 6 , have been repeatedly linked to worse clinical outcome, increased CV and worsened neurological decline in patients with aSAH (Mathiesen et al., 1997; Gruber et al., 2000; Kwon and Jeon, 2001; Hendryk et al., 2004; Chou et al., 2012). Investigation into the CSF of patients with aSAH has shown an increase in the number of activated neutrophils 
and monocytes, and that the robustness in this response correlates with delayed neurologic deterioration (Provencio et al., 2010; Moraes et al., 2015). Murine studies depleting peripheral neutrophils prior to the injury improved cognitive outcomes after aSAH (Provencio et al., 2016). Fever, increased white blood count, heart rate or tachypnea is seen in up to $87 \%$ of patients, and this inflammatory response increases the risk of developing delayed cerebral ischemia (Dhar and Diringer, 2008).

The critical roles played by Toll-like receptors (TLR) in SAH inflammation have been an area of active research in recent years. TLRs belong to the pattern recognition receptors family and play a well-described role in innate immunity and inflammatory responses (Lee and Lee, 2002). TLR4 is the one most studied in neuroinflammation and SAH. It is expressed in different cell types including microglia, neurons, astrocytes and endothelial cells. TLR4 (and other family members such as TLR2) can be activated by a number of ligands including heme and other components released by SAH (Lee and Lee, 2002; Jack et al., 2005).

Recently, in addition to heme, metHb was established as a ligand for TLR4 (Figueiredo et al., 2007; Kwon et al., 2015). In aSAH, TLR4 binding metHb/heme would result in the activation of a nuclear factor kappa beta (NFKB)-mediated proinflammatory cascade within microglia (or macrophages), DNA transcription, and production and release of TNF $\alpha$ and IL-1 $\beta$ (Lehnardt, 2010; Kwon et al., 2015; Lucke-Wold et al., 2016). Haptoglobin is relevant to this TLR4 inflammatory pathway since $\mathrm{Hp}-\mathrm{Hb}$ binding prevents conversion of the oxyHb to metHb, as well as extracellular release of heme from hemoglobin (Schaer et al., 2014). Other forms of hemoglobin, such as oxyHb, do not bind TLR4 (Gram et al., 2013; Schaer et al., 2014; Kwon et al., 2015). The TLR4 pathway in microglia results in the release of chemokines/cytokines and recruitment of activated peripheral macrophages and neutrophils into the CNS (Olson and Miller, 2004). Animal studies have shown that such microglial activation results in neuronal cell injury, and conversely depletion of microglia is neuroprotective (Hanafy, 2013; Schneider et al., 2015).

Macrophages also play a central role in regulating senescent RBCs and $\mathrm{Hb}$ clearance (Soares and Hamza, 2016). Although under maintenance conditions the erythrophagocyte acts in an anti-inflammatory capacity, excess free heme and iron can modulate macrophage phenotype into a proinflammatory M1 phenotype producing inflammatory cytokines and ROS (Soares and Hamza, 2016; Vinchi et al., 2016). This free heme/iron induced differentiation mechanism depends on TLR4 signaling pathway and ROS (Vinchi et al., 2016). Interestingly, heme scavengers and iron chelators, may mitigate macrophage polarization into the proinflammatory phenotype (Lin et al., 2010; Vinchi et al., 2016).

In disease states including diabetes and obesity, Hp 2-2 has been linked to a higher inflammatory state with elevations in WBC, TNF $\alpha$, and IL-6 (Lazalde et al., 2014; Costacou et al., 2015). The Hp 2-2 is also over-represented in autoimmune diseases including lupus and rheumatoid arthritis (MacKellar and Vigerust, 2016). In inflammatory states without CSF blood products, $\mathrm{TNF} \alpha$ appears to play a direct role in chronic cognitive changes and may be an independent factor in cognitive outcome after SAH (Rosi et al., 2004; Tobinick, 2009; Belarbi et al., 2012). In the aSAH population, correlation of the Hp genotype with the immune and inflammatory response has not been performed. Future studies should investigate the cytokine response and $\mathrm{TNF} \alpha$ levels with the Hp 2-2 genotype. In addition, this should be performed both systemically and intrathecally in an attempt to separate an inherent immune reactivity of the $\mathrm{Hp} \mathrm{2-2}$ vs. improved clearance of the Hp 1-1.

\section{BBB DISRUPTION}

The blood brain barrier (BBB) is formed by brain microvascular endothelial cells (ECs) with tight junctions and astrocyte end feet encircling ECs and with the participation of pericytes. The $\mathrm{BBB}$ plays a fundamental role in brain homeostasis by regulating the entry of intravascular molecules from the blood into the brain (Ueno, 2007). Studies into BBB dysfunction associated with $\mathrm{SAH}$ are relatively sparse compared with the literature on CV (Shigeno et al., 1982; Trojanowski, 1982; Peterson and Cardoso, 1983a,b; Dóczi et al., 1986). In animals, a significant $\mathrm{BBB}$ permeability change has been observed at the beginning as early as $3 \mathrm{~h}$ after $\mathrm{SAH}$, peaking at $48 \mathrm{~h}$, and normalizing on day 3 (Dóczi, 1985; Dóczi et al., 1986; Germanò et al., 2007). Multiple processes may contribute to BBB breakdown after $\mathrm{SAH}$, including EC necrosis/apoptosis, EC and/or pericyte contraction, and disassembly of tight junctions resulting in increased vascular permeability and formation of brain edema (Shigeno et al., 1982; Kago et al., 2006; Haorah et al., 2007; Kahles et al., 2007; Butt et al., 2011).

The EC has an active role following $\mathrm{SAH}$ and is critical to the BBB. Blood in the subarachnoid space rapidly stimulates the expression of cell adhesion molecules (CAMs) on the luminal surface of ECs (Gallia and Tamargo, 2006; Silva et al., 2009). This is coupled with overall reduction in protein synthesis (Foley et al., 1994), reduced expression of zona occludens 1 [ZO-1, a key cytoplasmic tight junction (TJ) accessory protein] altered expression of Claudin 5, and changes in the EC cytoskeleton, which all contribute to reduced integrity of the endothelium and BBB (Dóczi et al., 1986; Silva et al., 2009; Butt et al., 2011). CAMs and selectins expressions allow macrophages and neutrophils to bind the ECs and move in to subarachnoid space, where they phagocytose extravasated RBCs (erythrophagocytosis) and clear free $\mathrm{Hb}$ via CD163 mediated endocytosis of $\mathrm{Hb}: \mathrm{Hp}$ complexes (Gallia and Tamargo, 2006). These trapped macrophages and neutrophils then die and degranulate in the subarachnoid space resulting in the release of intracellular endothelins and oxygen free radicals, which contribute to inflammatory-induced EC damage and BBB dysfunction (Hijdra et al., 1988; Dietrich and Dacey, 2000; Claassen et al., 2001).

In animal models, EC and BBB damage has been demonstrated to occur after systemic or intrathecal infusion of Hb (Trojanowski, 1982; Peterson and Cardoso, 1983a,b; Dóczi et al., 1986; Butt et al., 2011). Studies in models of intracerebral hemorrhage also support the finding that that exposure to cell-free Hb leads to disruption of the BBB (Xi et al., 1998; Bhasin 
et al., 2002; Keep et al., 2008). In vivo experiments suggest that $\mathrm{Hp}$ binding to $\mathrm{Hb}$ mitigates EC cytotoxicity and cell membrane modification (Schaer C. A. et al., 2013; Schaer et al., 2014). There is also limited clinical evidence that an increased $\mathrm{Hp}$ concentration in disease states is also protective against EC injury (Dalan et al., 2017). Since Hp 2-2 patients have lower Hp serum levels and lower Hp antioxidant properties, these patients may be predisposed to increased EC injury and BBB dysfunction after SAH (Langlois and Delanghe, 1996; Melamed-Frank et al., 2001; Dalan et al., 2017).

Accumulating evidence suggests a role for MMP-9 in the early disruption of the BBB after SAH (Sehba et al., 2004; Guo et al., 2010). MMP-9 degrades the extracellular matrix of the cerebral microvessel basal lamina, which includes collagen IV, laminin, fibronectin, and inter-endothelial tight junction proteins such as ZO-1 (Sehba et al., 2004; Suzuki et al., 2010). In cerebral ischemia and $\mathrm{SAH}, \mathrm{TNF} \alpha$ is known to be increased and may correlate with a worse clinical outcome (Dong et al., 2009; Vecchione et al., 2009; Chou et al., 2012). As mentioned, the free Hb breakdown pathway triggers the release of TNF $\alpha$ through the TLR4/ NFKB pathway, and $\mathrm{TNF} \alpha$ is one cytokine known to increase MMP activity (Sun et al., 2010). The effect of Hp genotype on TNF $\alpha$ has not been studied in SAH (Lazalde et al., 2014).

No studies have been done to clearly elucidate the neuroprotective role of $\mathrm{Hp}$ in $\mathrm{BBB}$ dysfunction. But considering the fact that blood breakdown products such as $\mathrm{Hb} /$ heme and associated oxidative stress can contribute to BBB disruption, $\mathrm{Hp}$ mediated clearance of free $\mathrm{Hb}$ may possibly be one of the major mechanisms involved in preventing BBB dysfunction after SAH. In the context of intracerebral hemorrhage, experimentally induced hypohaptoglobinemia resulted in increased brain edema, indeed suggesting a protective role of $\mathrm{Hp}$ in $\mathrm{BBB}$ preservation (Zhao et al., 2009). One recent publication in diabetic patients suggested that Hp 2-2 patients, who have a lower plasma concentration of $\mathrm{Hp}$, have increased EC apoptotic rates (Dalan et al., 2017). Future studies are also warranted to determine the effects of $\mathrm{Hp}$ phenotypes in $\mathrm{EC}$ and/or pericyte damage/function and $\mathrm{BBB}$ breakdown. Interestingly, the properties of Hp1-1 (86 kDa) indicate a significant molecular size advantage over Hp 2-2 (170-900 kDa) which may help it cross cell membranes and the disrupted BBB, adding another potential protective advantage (Langlois and Delanghe, 1996; Melamed-Frank et al., 2001).

\section{CEREBRAL VASOSPASM}

Cerebral vasospasm occurs in most patients following aSAH, but only approximately $20-30 \%$ develop symptomatic cerebral vasospasm (Kassell et al., 1985). Cerebral vasospasm is related to disruption of the balance of vasodilators and vasoconstrictors (Pradilla et al., 2010). Nitric oxide (NO) is a vasodilator that is produced by ECs, neurons, and microglia and regulates cerebral vascular tone (Faraci and Brian, 1994). Following SAH, Hb released from erythrocytes can scavenge and reduce available NO, and cause delayed eNOS dysfunction (Sehba et al., 2000; Pluta, 2005, 2006; Azarov et al., 2008). Decreased levels of NO are associated with $\mathrm{CV}$, and experiments increasing $\mathrm{NO}$ reduce cerebral vasospasm (Gabikian et al., 2002; Sun et al., 2003; Pradilla et al., 2004; Pluta et al., 2005; Pluta, 2006; Sabri et al., 2013a).

In animal models, inducing expression of $\mathrm{Hp}$ or therapeutic infusion of $\mathrm{Hp}$ is protective of the vasoactive effects from intravascular hemolysis (Boretti et al., 2009). Although, it would be intuitive to assume that $\mathrm{Hp}$ binding reduces $\mathrm{NO}$ reactivity with $\mathrm{Hb}$, this does not appear to be the case (Azarov et al., 2008; Boretti et al., 2009). Rather Hp-Hb binding stabilizes the reduced $\mathrm{Hb}$ form and reduces $\mathrm{NO}$ scavenging by decreasing further free radical formation via improved $\mathrm{Hb}$ sequestration and augmented macrophage related clearance of $\mathrm{Hb}$ (Miller et al., 1997; Boretti et al., 2009; Levy et al., 2010; Cooper et al., 2013; Schaer et al., 2016).

Vasospasm is also intimately involved with inflammation and it has been shown that pro-inflammatory substances can trigger CV without blood in the CSF (Mori et al., 1994; Nagata et al., 1996; Recinos et al., 2006). CV is thought to be mediated through TLR4 activation/TNF $\alpha$, and it has been shown that inhibition of $\mathrm{TNF} \alpha$ prevents and resolves vasospasm in a murine model (Vecchione et al., 2009; Okada and Suzuki, 2017). In a mouse model of SAH, the administration of TLR4 antagonists intraventricularly prevented post-SAH neurological impairments and vasospasm (Kawakita et al., 2016). TLR4 knockout also suppressed vasospasm in a mouse blood injection model, with microglial TLR4 being necessary for induction of vasospasm most likely through $\mathrm{TNF} \alpha$ induction (Hanafy, 2013). As stated above, timely formation of $\mathrm{Hp}-\mathrm{Hb}$ complex plays a major role in preventing TLR4 activation. In a prospective study of thirty patients, those with a higher TLR4 levels on peripheral blood cells experienced increased occurrence of vasospasm and delayed cerebral ischemia (Ma et al., 2015).

Several clinical studies have shown a correlation with Hp 2-2 genotype and increased $\mathrm{CV}$ after aSAH (Borsody et al., 2006; Ohnishi et al., 2013; Leclerc et al., 2015). The mechanism for this benefit is not entirely clear. No study looking at Hp genotype and NO levels after aSAH has been performed. However, systemic diseases including diabetes and preeclampsia during pregnancy have indicated a correlation with Hp 2-2 genotype, lower NO levels and increased vascular tone (Sertório et al., 2013; Dahan et al., 2015). Whether Hp 2-2 has lower NO availability compared to $\mathrm{Hp} \mathrm{1-1} \mathrm{in}$ aSAH is a plausible, though speculative, mechanism. Similarly, whether TLR4 polymorphism can exacerbate SAH vasospasm in certain or all genotypes of $\mathrm{Hp}$ needs further investigation (Ferwerda et al., 2008).

\section{ARTERIAL MICROTHROMBOSIS}

It is known that SAH is associated with a hypercoagulable state, although this has been the subject of limited clinical investigation (Ikeda et al., 1997; Boluijt et al., 2015). Coagulation disorders can be divided into factors affecting (1) platelet activation, aggregation, and interaction with ECs, (2) blood coagulation, 
and (3) fibrinolysis (Cardenas et al., 2016). Few publications have attempted to address these factors comprehensively with contradictory results (Fujii et al., 1997; Ikeda et al., 1997; Boluijt et al., 2015). Nevertheless, studies have linked deviations in the coagulation and fibrinolytic cascade in patients with poor outcome after aSAH (Peltonen et al., 1997; Ji et al., 2014; Boluijt et al., 2015; Ramchand et al., 2016).

As might be expected in the setting of EC injury and a hypercoagulable state, arterial microthrombosis has been demonstrated in patients with aSAH in both human and in vivo animal model (Suzuki et al., 1990; Sehba et al., 2005; Stein et al., 2006; Friedrich et al., 2012; Sabri et al., 2012). Furthermore, the development of microthrombi is one mechanism contributing to poor outcome, and remains a target for therapeutic intervention (Suzuki et al., 1990; Stein et al., 2006; Vergouwen et al., 2008). Some authors have established that these thrombi are embolic, and on transcranial Doppler investigations, microembolic signals have been observed in up to $70 \%$ of those with $\mathrm{SAH}$ and this has been associated with delayed ischemia (Romano et al., 2002; Azarpazhooh et al., 2009). However, other authors have measured the frequency of microembolic signals and found their incidence to be much lower (Paschoal et al., 2015). The evidence seems to favor the development of local microthrombi in spastic, EC injured arterioles rather than systemic microemboli as the primary culprit for microthrombosis (Friedrich et al., 2012; Sabri et al., 2012).

Coagulation is inextricably linked to inflammatory cytokines known to be elevated after aSAH including $\mathrm{TNF} \alpha$ (via TLR4), which activates coagulation by decreasing protein kinase C production (an antithrombotic), increasing endothelial production of tissue factor (procoagulant), and increasing platelet activation (Valone and Epstein, 1988; Kirchhofer et al., 1994; Yamamoto et al., 1999; Wagner and Burger, 2003; Pircher et al., 2012). This platelet activation is also strongly inhibited by $\mathrm{NO}$, and aSAH is a depleted $\mathrm{NO}$ state induced by free $\mathrm{Hb}$ scavenging, and injury to ECs which produce NO (Sehba et al., 2000; Loscalzo, 2001; Wagner and Burger, 2003; Voetsch et al., 2004; Azarov et al., 2008; Boretti et al., 2009). Haptoglobin binding to $\mathrm{Hb}$ reduces inflammation and preserves $\mathrm{NO}$, and this may reduce hypercoagulable complications (Figueiredo et al., 2007; Azarov et al., 2008; Boretti et al., 2009; Vecchione et al., 2009; Lazalde et al., 2014; Schaer et al., 2014, 2016; Costacou et al., 2015). Unfortunately, clinical trials have not shown a clear benefit for antiplatelet agents or systemic anticoagulation, although a clinical trial evaluating low dose systemic heparin is ongoing (NCT02501434) (Siironen et al., 2003; van den Bergh et al., 2006; Dorhout Mees et al., 2007; Simard et al., 2013). One reason for this may be our current inability to identify patients at high risk for cerebral microthrombosis.

There is also a correlation between $\mathrm{Hp} 2-2$ and clinical prothrombotic sequelae, possibly secondary to increased

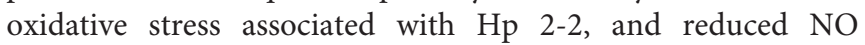
(Delanghe et al., 1997; Melamed-Frank et al., 2001; Touyz and Schiffrin, 2004; Voetsch et al., 2004; MacKellar and Vigerust, 2016). In a study of patients with spontaneous venous thromboembolism, it was found that the Hp 2-2 genotype was associated with a significantly increased risk, however this has never been studied in an aSAH population (Vormittag et al., 2005). Further evidence of hypercoagulability with Hp 2-2 is noted in cardiac literature indicating this genotype is associated with worse outcomes after cardiac bypass, and a higher rate of cardioembolic events following coronary angioplasty (Delanghe et al., 1997; Roguin et al., 2003). Clinical studies investigating spontaneous deep venous thrombosis formation in patients with aSAH show a high incidence (24\%), however a correlation to Hp genotype has not been investigated (Ray et al., 2009).

Whether the Hp2-2 genotype is associated with a clinically significant hypercoagulability profile in aSAH needs further investigation, though this genotype may create a synergistic effect with the aSAH-induced hypercoagulability. The indiscriminate use of antiplatelets and anticoagulants has not proven beneficial, and determining a genetic predisposition for a hypercoagulable state would by a significant benefit for clinical trial design and therapeutic intervention.

\section{SCIENTIFIC DISCREPANCIES}

In comparison to plasma, $\mathrm{Hp}$ is present in the CSF in low concentrations and may be rapidly overwhelmed by the amount of degraded erythrocytes in the CSF (Galea et al., 2012). There are still arguments within the community whether Hp and CD163 would be significantly present within the CNS to be able to deal with the supra-physiological levels of hemoglobin and methemoglobin. Systemic Hp expression is upregulated as an acute phase reactant following aSAH, though this increase does not clearly translate to the CSF (Galea et al., 2012). Nevertheless, it is known that oligodendrocytes are capable of producing some $\mathrm{Hp}$, and increased expression has the potential to serve as a therapeutic mechanism to reduce TLR4 activation and subsequent inflammation (Zhao et al., 2009). It also appears that Nuclear factor related factor 2 (Nrf2) activator in the context of $\mathrm{ICH}$ could robustly increase production of $\mathrm{Hb}$ not only in the blood but also in the brain, providing an intriguing solution for modulating Hp levels in the brain (Zhao et al., 2007, 2009).

There has also been interest in the role of CD163 as a mediator for varying effects of $\mathrm{Hp}-\mathrm{Hb}$ clearance. There does seem to be a higher affinity of $\mathrm{Hp} 2-2$ bound $\mathrm{Hb}$ for $\mathrm{CD} 163$; however, the internalization of the bound complex (Hp-Hb-CD163) may be higher for Hp1-1, although this is uncertain and requires further investigation (Kristiansen et al., 2001; Asleh et al., 2003; Na et al., 2005; Lipiski et al., 2013).

Most work on Hp genotype has focused on peripheral markers and not CSF. This remains a particular problem to aSAH since it is thought that the ictus and extravasation of blood into the CSF rapidly overwhelms the Hp binding capacity, regardless of phenotype (Galea et al., 2012). So why would Hp 1-1 phenotype be protective when Hp primarily exists in the circulation outside of the BBB? One explanation is that the size of $\mathrm{Hp} \mathrm{1-1} \mathrm{is}$ significantly smaller than $\mathrm{Hp} 2-2$, and it may cross the BBB into the CSF more easily, thus improving the hypo-Hp state (Langlois and Delanghe, 1996). However, this runs counter to data which shows a lower concentration of CSF Hp in patients with Hp 1-1, 
and this is suspected to be due to improved macrophage uptake (Galea et al., 2012).

Investigation into the temporal $\mathrm{Hp}$ concentration in the CSF after aSAH remains necessary to understand the utilization of $\mathrm{Hp}$ over time, clearance of $\mathrm{Hp}-\mathrm{Hb}$, and potentially movement of peripheral $\mathrm{Hp}$ into the CSF (and vice versa, $\mathrm{Hb}$ into the periphery). More reliable studies investigating bound CSF $\mathrm{Hp}$ (i.e., $\mathrm{Hb}-\mathrm{Hp}$ ) vs. free CSF $\mathrm{Hp}$ will help elucidate the mechanism of blood clearance and $\mathrm{Hp}$ protection after SAH.

The glymphatic pathway (or meningeal lymphatic system) for clearance of CSF solutes has become an interesting topic of investigation. There is evidence that increasing solute size limits glymphatic/lymphatic system clearance, and furthermore, aSAH reduces its function (Iliff et al., 2012; Gaberel et al., 2014; Bacyinski et al., 2017). Because Hp11 is smaller than $\mathrm{Hp2-2}$, it is possible that $\mathrm{Hp} 1-1$ bound hemoglobin is cleared more readily or does not obstruct clearance of other brain metabolites, though this requires further investigation.

Lastly, several limitations exist for experimental studies of $\mathrm{Hp}$ in mice. First, mice only have a single Hp genotype which corresponds to human $\mathrm{Hp} 1$, and therefore mice only express the Hp1-1 phenotype (Levy et al., 2006). Second, preclinical studies administering $\mathrm{Hp}$ utilize mixed haptoglobin solutions, consisting of multiple Hp phenotypes (Graw et al., 2016, 2017; Shi et al., 2016). These limitations make interpretation of Hp's role in brain hemorrhage pathophysiology difficult to assess. Future studies investigating $\mathrm{Hp}$ in aSAH and other cerebral hemorrhages should utilize Hp2 mutant mice in addition to the Hp1 expressing wild-type mice.

\section{REFERENCES}

Amiri, A. A., Hashemi-Soteh, M. B., Haghshenas, M. R., Daneshvar, F., Rastegar, A., and Farazmand, T. (2013). Haptoglobin polymorphism in individuals with type 2 diabetic microangiopathy. N. Am. J. Med. Sci. 5, 529-535. doi: 10.4103/1947-2714.118929

Andersen, C. B., Torvund-Jensen, M., Nielsen, M. J., de Oliveira, C. L., Hersleth, H. P., Andersen, N. H., et al. (2012). Structure of the haptoglobin-haemoglobin complex. Nature 489, 456-459. doi: 10.1038/nature11369

Ascenzi, P., Bocedi, A., Visca, P., Altruda, F., Tolosano, E., Beringhelli, T., et al. (2005). Hemoglobin and heme scavenging. IUBMB Life 57, 749-759. doi: 10.1080/15216540500380871

Asleh, R., Guetta, J., Kalet-Litman, S., Miller-Lotan, R., and Levy, A. P. (2005). Haptoglobin genotype- and diabetes-dependent differences in ironmediated oxidative stress in vitro and in vivo. Circ. Res. 96, 435-441. doi: 10.1161/01.RES.0000156653.05853.b9

Asleh, R., Marsh, S., Shilkrut, M., Binah, O., Guetta, J., Lejbkowicz, F., et al. (2003). Genetically determined heterogeneity in hemoglobin scavenging and susceptibility to diabetic cardiovascular disease. Circ. Res. 92, 1193-1200. doi: 10.1161/01.RES.0000076889.23082.F1

Azarov, I., He, X., Jeffers, A., Basu, S., Ucer, B., Hantgan, R. R., et al. (2008). Rate of nitric oxide scavenging by hemoglobin bound to haptoglobin. Nitric Oxide 18, 296-302. doi: 10.1016/j.niox.2008.02.006

Azarpazhooh, M. R., Velayati, A., Chambers, B. R., Nejad, H. M., and Nejad, P. S. (2009). Microembolic signals in subarachnoid hemorrhage. J. Clin. Neurosci. 16, 390-393. doi: 10.1016/j.jocn.2008.05.013

Bacyinski, A., Xu, M., Wang, W., and Hu, J. (2017). The paravascular pathway for brain waste clearance: current understanding, significance and controversy. Front. Neuroanat. 11:101. doi: 10.3389/fnana.2017.00101

\section{CONCLUSIONS AND FUTURE DIRECTIONS}

Lysis of RBCs and release of free $\mathrm{Hb} /$ heme drives the majority of the pathological process involved in delayed brain injury following SAH. Haptoglobin and its polymorphism has been extensively studied in other disease states, so much so that a human plasma-derived $\mathrm{Hp}$ was developed and is being utilized in the treatment of hemolysis (Schaer D. J. et al., 2013). Evidence from both preclinical and clinical studies support the notion that polymorphism in haptoglobin is a culprit in the delayed brain injury phase of SAH. Future efforts should focus on larger scale studies dealing with $\mathrm{Hp}$ polymorphism, on deciphering the molecular mechanisms by which $\mathrm{Hp}$ function and possibly testing $\mathrm{Hp}$ infusion as therapy for SAH patients suffering form delayed brain injury.

\section{AUTHOR CONTRIBUTIONS}

The conception of this article was by SB and JG. Both the writing and editing was performed by all authors. Authors SB, PP, DM, $\mathrm{HZ}$ contributed to the initial manuscript by writing individual portions of the manuscript. These were combined and edited by SB, and then submitted to HC, JG, PD, JC, and SD for expert editing and final preparation. Both JL and JA reviewed and critically edited the content of the manuscript.

\section{FUNDING}

This work was partially funded by the NIH grant 1R21NS095166, F31NS086441, and a Brain Aneurysm Foundation Award.

Bederson, J. B., Germano, I. M., and Guarino, L. (1995). Cortical blood flow and cerebral perfusion pressure in a new noncraniotomy model of subarachnoid hemorrhage in the rat. Stroke 26, 1086-1091; discussion: 91-92. doi: 10.1161/01.STR.26.6.1086

Belarbi, K., Jopson, T., Tweedie, D., Arellano, C., Luo, W., Greig, N. H., et al. (2012). TNF-alpha protein synthesis inhibitor restores neuronal function and reverses cognitive deficits induced by chronic neuroinflammation. J. Neuroinflammation 9:23. doi: 10.1186/1742-2094-9-23

Bhasin, R. R., Xi, G., Hua, Y., Keep, R. F., and Hoff, J. T. (2002). Experimental intracerebral hemorrhage: effect of lysed erythrocytes on brain edema and blood-brain barrier permeability. Acta Neurochir. Suppl. 81, 249-251. doi: 10.1007/978-3-7091-6738-0_65

Boluijt, J., Meijers, J. C., Rinkel, G. J., and Vergouwen, M. D. (2015). Hemostasis and fibrinolysis in delayed cerebral ischemia after aneurysmal subarachnoid hemorrhage: a systematic review. J. Cereb. Blood Flow Metab. 35, 724-733. doi: $10.1038 /$ jcbfm.2015.13

Boretti, F. S., Buehler, P. W., D’Agnillo, F., Kluge, K., Glaus, T., Butt, O. I., et al. (2009). Sequestration of extracellular hemoglobin within a haptoglobin complex decreases its hypertensive and oxidative effects in dogs and guinea pigs. J. Clin. Invest. 119, 2271-2280. doi: 10.1172/ JCI39115

Borsody, M., Burke, A., Coplin, W., Miller-Lotan, R., and Levy, A. (2006). Haptoglobin and the development of cerebral artery vasospasm after subarachnoid hemorrhage. Neurology 66, 634-640. doi: 10.1212/01.wnl.0000200781.62172.1d

Boutaud, O., Moore, K. P., Reeder, B. J., Harry, D., Howie, A. J., Wang, S., et al. (2010). Acetaminophen inhibits hemoprotein-catalyzed lipid peroxidation and attenuates rhabdomyolysis-induced renal failure. Proc. Natl. Acad. Sci. U.S.A. 107, 2699-2704. doi: 10.1073/pnas.0910174107 
Buehler, P. W., Abraham, B., Vallelian, F., Linnemayr, C., Pereira, C. P., Cipollo, J. F., et al. (2009). Haptoglobin preserves the CD163 hemoglobin scavenger pathway by shielding hemoglobin from peroxidative modification. Blood 113, 2578-2586. doi: 10.1182/blood-2008-08-174466

Butt, O. I., Buehler, P. W., and D'Agnillo, F. (2011). Blood-brain barrier disruption and oxidative stress in guinea pig after systemic exposure to modified cellfree hemoglobin. Am. J. Pathol. 178, 1316-1328. doi: 10.1016/j.ajpath.2010. 12.006

Cabrales, P., and Friedman, J. M. (2013). HBOC vasoactivity: interplay between nitric oxide scavenging and capacity to generate bioactive nitric oxide species. Antioxid. Redox Signal. 18, 2284-2297. doi: 10.1089/ars.2012. 5099.test

Cardenas, J. C., Rein-Smith, C. M., and Church, F. C. (2016). "Overview of blood coagulation and the pathophysiology of blood coagulation disorders," in Encyclopedia of Cell Biology, eds R. A. Bradshaw and P. Stahl (Waltham, MA: Elsevier/AP), 714-722.

Chou, S. H., Feske, S. K., Atherton, J., Konigsberg, R. G., De Jager, P. L., Du, R., et al. (2012). Early elevation of serum tumor necrosis factor-alpha is associated with poor outcome in subarachnoid hemorrhage. J. Investig. Med. 60, 1054-1058. doi: 10.2310/JIM.0b013e3182686932

Claassen, J., Bernardini, G. L., Kreiter, K., Bates, J., Du, Y. E., Copeland, D., et al. (2001). Effect of cisternal and ventricular blood on risk of delayed cerebral ischemia after subarachnoid hemorrhage: the Fisher scale revisited. Stroke 32, 2012-2020. doi: 10.1161/hs0901.095677

Claassen, J., Carhuapoma, J. R., Kreiter, K. T., Du, E. Y., Connolly, E. S., and Mayer, S. A. (2002). Global cerebral edema after subarachnoid hemorrhage: frequency, predictors, and impact on outcome. Stroke 33, 1225-1232. doi: 10.1161/01.STR.0000015624.29071.1F

Cooper, C. E., Schaer, D. J., Buehler, P. W., Wilson, M. T., Reeder, B. J., Silkstone, G., et al. (2013). Haptoglobin binding stabilizes hemoglobin ferryl iron and the globin radical on tyrosine beta145. Antioxid. Redox Signal. 18, 2264-2273. doi: 10.1089/ars.2012.4547.test

Costacou, T., Evans, R. W., and Orchard, T. J. (2015). Does the concentration of oxidative and inflammatory biomarkers differ by haptoglobin genotype in type 1 diabetes? Antioxid. Redox Signal. 23, 1439-1444. doi: 10.1089/ars.2015.6355

Dahan, I., Farber, E., Thauho, N., Nakhoul, N., Francis, A., Awawde, M., et al. (2015). Interaction between the haptoglobin 2 phenotype and diabetes mellitus on systolic pulmonary arterial pressure and nitric oxide bioavailability in hemodialysis patients. J. Diabetes Res. 2015:613860. doi: 10.1155/2015/613860

Dalan, R., Liew, H., Goh, L. L., Gao, X., Chew, D. E., Boehm, B. O., et al. (2016). The haptoglobin 2-2 genotype is associated with inflammation and carotid artery intima-media thickness. Diab. Vasc. Dis. Res. 13, 373-376. doi: $10.1177 / 1479164116645247$

Dalan, R., Liu, X., Goh, L. L., Bing, S., and Luo, K. Q. (2017). Endothelial cell apoptosis correlates with low haptoglobin concentrations in diabetes. Diab. Vasc. Dis. Res. 14, 534-539. doi: 10.1177/1479164117719827

Delanghe, J., Cambier, B., Langlois, M., De Buyzere, M., Neels, H., De Bacquer, D., et al. (1997). Haptoglobin polymorphism, a genetic risk factor in coronary artery bypass surgery. Atherosclerosis 132, 215-219. doi: 10.1016/S0021-9150(97)00089-0

Dhar, R., and Diringer, M. N. (2008). The burden of the systemic inflammatory response predicts vasospasm and outcome after subarachnoid hemorrhage. Neurocrit. Care 8, 404-412. doi: 10.1007/s12028-008-9054-2

Dhar, R., Scalfani, M. T., Blackburn, S., Zazulia, A. R., Videen, T., and Diringer, M. (2012). Relationship between angiographic vasospasm and regional hypoperfusion in aneurysmal subarachnoid hemorrhage. Stroke 43, 1788-1794. doi: 10.1161/STROKEAHA.111.646836

Dietrich, H. H., and Dacey, R. G. Jr. (2000). Molecular keys to the problems of cerebral vasospasm. Neurosurgery 46, 517-530. doi: 10.1097/00006123-200003000-00001

Dóczi, T. (1985). The pathogenetic and prognostic significance of bloodbrain barrier damage at the acute stage of aneurysmal subarachnoid haemorrhage. Clin. Exp. Stud. Acta Neurochir 77, 110-132. doi: 10.1007/BF014 76215

Dóczi, T., Joó, F., Adám, G., Bozóky, B., and Szerdahelyi, P. (1986). Bloodbrain barrier damage during the acute stage of subarachnoid hemorrhage, as exemplified by a new animal model. Neurosurgery 18, 733-739. doi: 10.1227/00006123-198606000-00010
Dong, X., Song, Y. N., Liu, W. G., and Guo, X. L. (2009). Mmp-9, a potential target for cerebral ischemic treatment. Curr. Neuropharmacol. 7, 269-275. doi: 10.2174/157015909790031157

Dorhout Mees, S. M., van den Bergh, W. M., Algra, A., and Rinkel, G. J. (2007). Antiplatelet therapy for aneurysmal subarachnoid haemorrhage. Cochrane Database Syst. Rev.17:CD006184. doi: 10.1002/14651858.CD006184.pub2

Dreier, J. P., Major, S., Manning, A., Woitzik, J., Drenckhahn, C., Steinbrink, J., et al. (2009). Cortical spreading ischaemia is a novel process involved in ischaemic damage in patients with aneurysmal subarachnoid haemorrhage. Brain 132(Pt 7), 1866-1881. doi: 10.1093/brain/awp102

Faraci, F. M., and Brian, J. E. Jr. (1994). Nitric oxide and the cerebral circulation. Stroke 25, 692-703. doi: 10.1161/01.STR.25.3.692

Ferwerda, B., McCall, M. B., Verheijen, K., Kullberg, B. J., van der Ven, A. J., Van der Meer, J. W., et al. (2008). Functional consequences of toll-like receptor 4 polymorphisms. Mol. Med. 14, 346-352. doi: 10.2119/2007-00135.Ferwerda

Figueiredo, R. T., Fernandez, P. L., Mourao-Sa, D. S., Porto, B. N., Dutra, F. F., Alves, L. S., et al. (2007). Characterization of heme as activator of Toll-like receptor 4. J. Biol. Chem. 282, 20221-20229. doi: 10.1074/jbc.M610737200

Foley, P. L., Takenaka, K., Kassell, N. F., and Lee, K. S. (1994). Cytotoxic effects of bloody cerebrospinal fluid on cerebral endothelial cells in culture. J. Neurosurg. 81, 87-92. doi: 10.3171/jns.1994.81.1.0087

Foreman, B. (2016). The pathophysiology of delayed cerebral ischemia. J. Clin. Neurophysiol. 33, 174-182. doi: 10.1097/WNP.0000000000000273

Friedrich, B., Muller, F., Feiler, S., Scholler, K., and Plesnila, N. (2012). Experimental subarachnoid hemorrhage causes early and long-lasting microarterial constriction and microthrombosis: an in-vivo microscopy study. J. Cereb. Blood Flow Metab. 32, 447-455. doi: 10.1038/jcbfm.2011.154

Fujii, Y., Takeuchi, S., Sasaki, O., Minakawa, T., Koike, T., and Tanaka, R. (1997). Serial changes of hemostasis in aneurysmal subarachnoid hemorrhage with special reference to delayed ischemic neurological deficits. J. Neurosurg. 86, 594-602. doi: 10.3171/jns.1997.86.4.0594

Gaberel, T., Gakuba, C., Goulay, R., Martinez De Lizarrondo, S., Hanouz, J. L., Emery, E., et al. (2014). Impaired glymphatic perfusion after strokes revealed by contrast-enhanced MRI: a new target for fibrinolysis? Stroke 45, 3092-3096. doi: 10.1161/STROKEAHA.114.006617

Gabikian, P., Clatterbuck, R. E., Eberhart, C. G., Tyler, B. M., Tierney, T. S., and Tamargo, R. J. (2002). Prevention of experimental cerebral vasospasm by intracranial delivery of a nitric oxide donor from a controlled-release polymer: toxicity and efficacy studies in rabbits and rats. Stroke 33, 2681-2686. doi: 10.1161/01.STR.0000033931.62992.B1

Galea, J., Cruickshank, G., Teeling, J. L., Boche, D., Garland, P., Perry, V. H., et al. (2012). The intrathecal CD163-haptoglobin-hemoglobin scavenging system in subarachnoid hemorrhage. J. Neurochem. 121, 785-792. doi: 10.1111/j.1471-4159.2012.07716.x

Gallia, G. L., and Tamargo, R. J. (2006). Leukocyte-endothelial cell interactions in chronic vasospasm after subarachnoid hemorrhage. Neurol. Res. 28, 750-758. doi: $10.1179 / 016164106 \mathrm{X} 152025$

Germanò, A., Caffo, M., Angileri, F. F., Arcadi, F., Newcomb-Fernandez, J., Caruso, G., et al. (2007). NMDA receptor antagonist felbamate reduces behavioral deficits and blood-brain barrier permeability changes after experimental subarachnoid hemorrhage in the rat. J. Neurotrauma 24, 732-744. doi: 10.1089/neu.2006.0181

Goldenstein, H., Levy, N. S., and Levy, A. P. (2012). Haptoglobin genotype and its role in determining heme-iron mediated vascular disease. Pharmacol. Res. 66, 1-6. doi: 10.1016/j.phrs.2012.02.011

Gomis, P., Graftieaux, J. P., Sercombe, R., Hettler, D., Scherpereel, B., and Rousseaux, P. (2010). Randomized, double-blind, placebo-controlled, pilot trial of high-dose methylprednisolone in aneurysmal subarachnoid hemorrhage. J. Neurosurg. 112, 681-688. doi: 10.3171/2009.4.JNS081377

Gonzales, R., Auclair, C., Voisin, E., Gautero, H., Dhermy, D., and Boivin, P. (1984). Superoxide dismutase, catalase, and glutathione peroxidase in red blood cells from patients with malignant diseases. Cancer Res. 44, 4137-4139.

Gram, M., Sveinsdottir, S., Ruscher, K., Hansson, S. R., Cinthio, M., Akerström, B., et al. (2013). Hemoglobin induces inflammation after preterm intraventricular hemorrhage by methemoglobin formation. J. Neuroinflammation 10:100. doi: 10.1186/1742-2094-10-100

Graw, J. A., Mayeur, C., Rosales, I., Liu, Y., Sabbisetti, V. S., Riley, F. E., et al. (2016). Haptoglobin or hemopexin therapy prevents acute adverse effects of 
resuscitation after prolonged storage of red cells. Circulation 134, 945-960. doi: 10.1161/CIRCULATIONAHA.115.019955

Graw, J. A., Yu, B., Rezoagli, E., Warren, H. S., Buys, E. S., Bloch, D. B., et al. (2017). Endothelial dysfunction inhibits the ability of haptoglobin to prevent hemoglobin-induced hypertension. Am. J. Physiol. Heart Circ. Physiol. 312, H1120-H1127. doi: 10.1152/ajpheart.00851.2016

Gruber, A., Rössler, K., Graninger, W., Donner, A., Illievich, M. U., and Czech, T. (2000). Ventricular cerebrospinal fluid and serum concentrations of sTNFRI, IL-1ra, and IL-6 after aneurysmal subarachnoid hemorrhage. J. Neurosurg. Anesthesiol. 12, 297-306. doi: 10.1097/00008506-200010000-00001

Guo, Z., Sun, X., He, Z., Jiang, Y., Zhang, X., and Zhang, J. H. (2010). Matrix metalloproteinase-9 potentiates early brain injury after subarachnoid hemorrhage. Neurol. Res. 32, 715-720. doi: 10.1179/016164109X12478302362491

Hanafy, K. A. (2013). The role of microglia and the TLR4 pathway in neuronal apoptosis and vasospasm after subarachnoid hemorrhage. J. Neuroinflammation 10:83. doi: 10.1186/1742-2094-10-83

Haorah, J., Ramirez, S. H., Schall, K., Smith, D., Pandya, R., and Persidsky, Y. (2007). Oxidative stress activates protein tyrosine kinase and matrix metalloproteinases leading to blood-brain barrier dysfunction. J. Neurochem. 101, 566-576. doi: 10.1111/j.1471-4159.2006.04393.x

Hendryk, S., Jarzab, B., and Josko, J. (2004). Increase of the IL-1 beta and IL-6 levels in CSF in patients with vasospasm following aneurysmal SAH. Neuro Endocrinol. Lett. 25, 141-147.

Hijdra, A., van Gijn, J., Nagelkerke, N. J., Vermeulen, M., and van Crevel, H. (1988). Prediction of delayed cerebral ischemia, rebleeding, and outcome after aneurysmal subarachnoid hemorrhage. Stroke 19, 1250-1256. doi: 10.1161/01.STR.19.10.1250

Hop, J. W., Rinkel, G. J., Algra, A., and van Gijn, J. (1997). Case-fatality rates and functional outcome after subarachnoid hemorrhage: a systematic review. Stroke 28, 660-664. doi: 10.1161/01.STR.28.3.660

Ikeda, K., Asakura, H., Futami, K., and Yamashita, J. (1997). Coagulative and fibrinolytic activation in cerebrospinal fluid and plasma after subarachnoid hemorrhage. Neurosurgery 41, 344-349; discussion: 9-50. doi: 10.1097/00006123-199708000-00002

Iliff, J. J., Wang, M., Liao, Y., Plogg, B. A., Peng, W., Gundersen, G. A., et al. (2012). A paravascular pathway facilitates CSF flow through the brain parenchyma and the clearance of interstitial solutes, including amyloid beta. Sci. Transl. Med. 4:147ra11. doi: 10.1126/scitranslmed.3003748

Jack, C. S., Arbour, N., Manusow, J., Montgrain, V., Blain, M., McCrea, E., et al. (2005). TLR signaling tailors innate immune responses in human microglia and astrocytes. J. Immunol. 175, 4320-4330. doi: 10.4049/jimmunol.175.7.4320

Ji, Y., Meng, Q. H., and Wang, Z. G. (2014). Changes in the coagulation and fibrinolytic system of patients with subarachnoid hemorrhage. Neurol. Med. Chir. 54, 457-464. doi: 10.2176/nmc.oa2013-0006

Kago, T., Takagi, N., Date, I., Takenaga, Y., Takagi, K., and Takeo, S. (2006). Cerebral ischemia enhances tyrosine phosphorylation of occludin in brain capillaries. Biochem. Biophys. Res. Commun. 339, 1197-1203. doi: 10.1016/j.bbrc.2005.11.133

Kahles, T., Luedike, P., Endres, M., Galla, H. J., Steinmetz, H., Busse, R., et al. (2007). NADPH oxidase plays a central role in bloodbrain barrier damage in experimental stroke. Stroke 38, 3000-3006. doi: 10.1161/STROKEAHA.107.489765

Kantor, E., Bayir, H., Ren, D., Provencio, J. J., Watkins, L., Crago, E., et al. (2014). Haptoglobin genotype and functional outcome after aneurysmal subarachnoid hemorrhage. J. Neurosurg. 120, 386-390. doi: 10.3171/2013.10.JNS13219

Kassell, N. F., Sasaki, T., Colohan, A. R., and Nazar, G. (1985). Cerebral vasospasm following aneurysmal subarachnoid hemorrhage. Stroke 16, 562-572. doi: 10.1161/01.STR.16.4.562

Kawakita, F., Fujimoto, M., Liu, L., Nakano, F., Nakatsuka, Y., and Suzuki, H. (2016). Effects of Toll-Like receptor 4 antagonists against cerebral vasospasm after experimental subarachnoid hemorrhage in mice. Mol Neurobiol. 54, 6624-6633. doi: 10.1007/s12035-016-0178-7

Keep, R. F., Xiang, J., Ennis, S. R., Andjelkovic, A., Hua, Y., Xi, G., et al. (2008). Blood-brain barrier function in intracerebral hemorrhage. Acta Neurochir. Suppl. 105, 73-77. doi: 10.1007/978-3-211-09469-3_15

Kirchhofer, D., Tschopp, T. B., Hadváry, P., and Baumgartner, H. R. (1994). Endothelial cells stimulated with tumor necrosis factor-alpha express varying amounts of tissue factor resulting in inhomogenous fibrin deposition in a native blood flow system. Effects of thrombin inhibitors. J. Clin. Invest. 93, 2073-2083. doi: 10.1172/JCI117202

Kristiansen, M., Graversen, J. H., Jacobsen, C., Sonne, O., Hoffman, H. J., Law, S K., et al. (2001). Identification of the haemoglobin scavenger receptor. Nature 409, 198-201. doi: 10.1038/35051594

Kwon, K. Y., and Jeon, B. C. (2001). Cytokine levels in cerebrospinal fluid and delayed ischemic deficits in patients with aneurysmal subarachnoid hemorrhage. J. Korean Med. Sci. 16, 774-780. doi: 10.3346/jkms.2001.16.6.774

Kwon, M. S., Woo, S. K., Kurland, D. B., Yoon, S. H., Palmer, A. F., Banerjee, U., et al. (2015). Methemoglobin is an endogenous toll-like receptor 4 ligand-relevance to subarachnoid hemorrhage. Int. J. Mol. Sci. 16, 5028-5046. doi: 10.3390/ijms16035028

Langlois, M. R., and Delanghe, J. R. (1996). Biological and clinical significance of haptoglobin polymorphism in humans. Clin. Chem. 42, 1589-1600.

Lazalde, B., Huerta-Guerrero, H. M., Simental-Mendia, L. E., Rodriguez-Moran, M., and Guerrero-Romero, F. (2014). Haptoglobin 2-2 genotype is associated with TNF- alpha and IL-6 levels in subjects with obesity. Dis. Markers 2014:912756. doi: 10.1155/2014/912756

Leclerc, J. L., Blackburn, S., Neal, D., Mendez, N. V., Wharton, J. A., Waters, M. F., et al. (2015). Haptoglobin phenotype predicts the development of focal and global cerebral vasospasm and may influence outcomes after aneurysmal subarachnoid hemorrhage. Proc. Natl. Acad. Sci. U.S.A. 112, 1155-1160. doi: 10.1073/pnas.1412833112

Lee, J. Y., Keep, R. F., He, Y., Sagher, O., Hua, Y., and Xi, G. (2010). Hemoglobin and iron handling in brain after subarachnoid hemorrhage and the effect of deferoxamine on early brain injury. J. Cereb. Blood Flow Metab. 30, 1793-1803. doi: $10.1038 /$ jcbfm. 2010.137

Lee, S. J., and Lee, S. (2002). Toll-like receptors and inflammation in the CNS. Curr. Drug Targets Inflamm. Allergy 1, 181-191. doi: 10.2174/1568010023344698

Lee, T. H., Kim, S. U., Yu, S. L., Kim, S. H., Park, D. S., Moon, H. B., et al. (2003). Peroxiredoxin II is essential for sustaining life span of erythrocytes in mice. Blood 101, 5033-5038. doi: 10.1182/blood-2002-08-2548

Lehnardt, S. (2010). Innate immunity and neuroinflammation in the CNS: the role of microglia in Toll-like receptor-mediated neuronal injury. Glia 58, 253-263. doi: 10.1002/glia.20928

Levy, A., Levy, J. E., Kalet-Litman, S., Miller-Lotan, R., Levy, N. S., Asaf, R., et al. (2006). Haptoglobin genotype is a determinant of iron, lipid peroxidation, and macrophage accumulation in the atherosclerotic plaque. Arterioscler. Thromb. Vasc. Biol. 27, 134-140. doi: 10.1161/01.ATV.0000251020.24399.a2

Levy, A. P., Asleh, R., Blum, S., Levy, N. S., Miller-Lotan, R., Kalet-Litman, S., et al. (2010). Haptoglobin: basic and clinical aspects. Antioxid. Redox Signal. 12, 293-304. doi: 10.1089/ars.2009.2793

Levy, A. P., Purushothaman, K. R., Levy, N. S., Purushothaman, M., Strauss, M., Asleh, R., et al. (2007). Downregulation of the hemoglobin scavenger receptor in individuals with diabetes and the Hp 2-2 genotype: implications for the response to intraplaque hemorrhage and plaque vulnerability. Circ. Res. 101, 106-110. doi: 10.1161/CIRCRESAHA.107.149435

Lin, T., Kwak, Y. H., Sammy, F., He, P., Thundivalappil, S., Sun, G., et al. (2010). Synergistic inflammation is induced by blood degradation products with microbial Toll-like receptor agonists and is blocked by hemopexin. J. Infect. Dis. 202, 624-632. doi: 10.1086/654929

Lipiski, M., Deuel, J. W., Baek, J. H., Engelsberger, W. R., Buehler, P. W., and Schaer, D. J. (2013). Human Hp1-1 and Hp2-2 phenotype-specific haptoglobin therapeutics are both effective in vitro and in guinea pigs to attenuate hemoglobin toxicity. Antioxid. Redox Signal. 19, 1619-1633. doi: 10.1089/ars.2012.5089

Lisk, C., Kominsky, D., Ehrentraut, S., Bonaventura, J., Nuss, R., Hassell, K., et al. (2013). Hemoglobin-induced endothelial cell permeability is controlled, in part, via a myeloid differentiation primary response gene-88dependent signaling mechanism. Am. J. Respir. Cell Mol. Biol. 49, 619-626. doi: $10.1165 / \mathrm{rcmb} .2012-04400 \mathrm{OC}$

Loscalzo, J. (2001). Nitric oxide insufficiency, platelet activation, and arterial thrombosis. Circ. Res. 88, 756-762. doi: 10.1161/hh0801.089861

Lucke-Wold, B. P., Logsdon, A. F., Manoranjan, B., Turner, R. C., McConnell, E., Vates, G. E., et al. (2016). Aneurysmal subarachnoid hemorrhage and neuroinflammation: a comprehensive review. Int. J. Mol. Sci. 17:497. doi: 10.3390/ijms 17040497 
Ma, C., Zhou, W., Yan, Z., Qu, M., and Bu, X. (2015). Toll-like Receptor 4 (TLR4) is associated with cerebral vasospasm and delayed cerebral ischemia in aneurysmal subarachnoid hemorrhage. Neurol. Med. Chir. 55, 878-884. doi: 10.2176/nmc.oa.2015-0077

Macdonald, R. L., Higashida, R. T., Keller, E., Mayer, S. A., Molyneux, A., Raabe, A., et al. (2011). Clazosentan, an endothelin receptor antagonist, in patients with aneurysmal subarachnoid haemorrhage undergoing surgical clipping: a randomised, double-blind, placebo-controlled phase 3 trial (CONSCIOUS-2). Lancet Neurol. 10, 618-625. doi: 10.1016/S1474-4422(11)70108-9

Macdonald, R. L., and Weir, B. K. (1991). A review of hemoglobin and the pathogenesis of cerebral vasospasm. Stroke 22, 971-982. doi: 10.1161/01.STR.22.8.971

MacKellar, M., and Vigerust, D. J. (2016). Role of haptoglobin in health and disease: a focus on diabetes. Clin. Diabetes 34, 148-157. doi: 10.2337/diaclin.34.3.148

Mathiesen, T., Edner, G., Ulfarsson, E., and Andersson, B. (1997). Cerebrospinal fluid interleukin-1 receptor antagonist and tumor necrosis factoralpha following subarachnoid hemorrhage. J. Neurosurg. 87, 215-220. doi: 10.3171/jns.1997.87.2.0215

Melamed-Frank, M., Lache, O., Enav, B. I., Szafranek, T., Levy, N. S., Ricklis, R. M., et al. (2001). Structure-function analysis of the antioxidant properties of haptoglobin. Blood 98, 3693-3698. doi: 10.1182/blood.V98.13.3693

Miller, Y. I., Altamentova, S. M., and Shaklai, N. (1997). Oxidation of lowdensity lipoprotein by hemoglobin stems from a heme-initiated globin radical: antioxidant role of haptoglobin. Biochemistry 36, 12189-12198. doi: 10.1021/bi970258a

Moraes, L., Grille, S., Morelli, P., Mila, R., Trias, N., Brugnini, A., et al. (2015). Immune cells subpopulations in cerebrospinal fluid and peripheral blood of patients with Aneurysmal Subarachnoid Hemorrhage. Springerplus 4:195. doi: 10.1186/s40064-015-0970-2

Mori, T., Nagata, K., Ishida, T., Nikaido, H., Kobayashi, E., Sasaki, T., et al. (1994). Sequential morphological changes of the constrictive basilar artery in a canine model of experimental cerebral vasospasm by talc injection. J. Vet. Med. Sci. 56, 535-540. doi: 10.1292/jvms.56.535

Na, N., Ouyang, J., Taes, Y. E., and Delanghe, J. R. (2005). Serum free hemoglobin concentrations in healthy individuals are related to haptoglobin type. Clin. Chem. 51, 1754-1755. doi: 10.1373/clinchem.2005.055657

Nagababu, E., Chrest, F. J., and Rifkind, J. M. (2003). Hydrogen-peroxideinduced heme degradation in red blood cells: the protective roles of catalase and glutathione peroxidase. Biochim. Biophys. Acta 1620, 211-217. doi: 10.1016/S0304-4165(02)00537-8

Nagata, K., Sasaki, T., Mori, T., Nikaido, H., Kobayashi, E., Kim, P., et al. (1996). Cisternal talc injection in dog can induce delayed and prolonged arterial constriction resembling cerebral vasospasm morphologically and pharmacologically. Surg. Neurol. 45, 442-447. doi: 10.1016/0090-3019(95)00455-6

Neil-Dwyer, G., Lang, D. A., Doshi, B., Gerber, C. J., and Smith, P. W. (1994). Delayed cerebral ischaemia: the pathological substrate. Acta Neurochir. 131, 137-145. doi: 10.1007/BF01401464

Ohnishi, H., Iihara, K., Kaku, Y., Yamauchi, K., Fukuda, K., Nishimura, K., et al. (2013). Haptoglobin phenotype predicts cerebral vasospasm and clinical deterioration after aneurysmal subarachnoid hemorrhage. J. Stroke Cerebrovasc. Dis. 22, 520-526. doi: 10.1016/j.jstrokecerebrovasdis.2013.02.005

Okada, T., and Suzuki, H. (2017). Toll-like receptor 4 as a possible therapeutic target for delayed brain injuries after aneurysmal subarachnoid hemorrhage. Neural Regen. Res. 12, 193-196. doi: 10.4103/1673-5374.200795

Olson, J. K., and Miller, S. D. (2004). Microglia initiate central nervous system innate and adaptive immune responses through multiple TLRs. J. Immunol. 173, 3916-3924. doi: 10.4049/jimmunol.173.6.3916

Panter, S. S., Sadrzadeh, S. M., Hallaway, P. E., Haines, J. L., Anderson, V. E., and Eaton, J. W. (1985). Hypohaptoglobinemia associated with familial epilepsy. J. Exp. Med. 161, 748-754. doi: 10.1084/jem.161.4.748

Paschoal, F. M. Jr., de Almeida Lins Ronconi, K., de Lima Oliveira, M., Nogueira Rde, C., Paschoal, E. H., Teixeira, M. J., et al. (2015). Embolic signals during routine transcranial Doppler ultrasonography in aneurysmal subarachnoid hemorrhage. Biomed Res. Int. 2015:153714. doi: 10.1155/2015/153714

Peltonen, S., Juvela, S., Kaste, M., and Lassila, R. (1997). Hemostasis and fibrinolysis activation after subarachnoid hemorrhage. J. Neurosurg. 87, 207-214. doi: 10.3171/jns.1997.87.2.0207
Peterson, E. W., and Cardoso, E. R. (1983a). The blood-brain barrier following experimental subarachnoid hemorrhage. Part 1: response to insult caused by arterial hypertension. J. Neurosurg. 58, 338-344. doi: $10.3171 /$ jns.1983.58.3.0338

Peterson, E. W., and Cardoso, E. R. (1983b). The blood-brain barrier following experimental subarachnoid hemorrhage. Part 2: response to mercuric chloride infusion. J. Neurosurg. 58, 345-351. doi: 10.3171/jns.1983.58.3.0345

Pircher, J., Merkle, M., Wornle, M., Ribeiro, A., Czermak, T., Stampnik, Y., et al. (2012). Prothrombotic effects of tumor necrosis factor alpha in vivo are amplified by the absence of TNF-alpha receptor subtype 1 and require TNF-alpha receptor subtype 2. Arthritis Res. Ther. 14:R225. doi: 10.1186/ar4064

Pluta, R. M. (2005). Delayed cerebral vasospasm and nitric oxide: review, new hypothesis, and proposed treatment. Pharmacol. Ther. 105, 23-56. doi: 10.1016/j.pharmthera.2004.10.002

Pluta, R. M. (2006). Dysfunction of nitric oxide synthases as a cause and therapeutic target in delayed cerebral vasospasm after SAH. Neurol. Res. 28, 730-737. doi: 10.1179/016164106X152052

Pluta, R. M., Dejam, A., Grimes, G., Gladwin, M. T., and Oldfield, E. H. (2005). Nitrite infusions to prevent delayed cerebral vasospasm in a primate model of subarachnoid hemorrhage. JAMA 293, 1477-1484. doi: 10.1001/jama.293.12.1477

Pradilla, G., Chaichana, K. L., Hoang, S., Huang, J., and Tamargo, R. J. (2010). Inflammation and cerebral vasospasm after subarachnoid hemorrhage. Neurosurg. Clin. N. Am. 21, 365-379. doi: 10.1016/j.nec.2009.10.008

Pradilla, G., Thai, Q. A., Legnani, F. G., Hsu, W., Kretzer, R. M., Wang, P. P., et al. (2004). Delayed intracranial delivery of a nitric oxide donor from a controlled-release polymer prevents experimental cerebral vasospasm in rabbits. Neurosurgery 55, 1393-1399; discussion: 9-400. doi: 10.1227/01.NEU.0000143615.26102.1A

Provencio, J. J., Fu, X., Siu, A., Rasmussen, P. A., Hazen, S. L., and Ransohoff, R. M. (2010). CSF neutrophils are implicated in the development of vasospasm in subarachnoid hemorrhage. Neurocrit. Care 12, 244-251. doi: 10.1007/s12028-009-9308-7

Provencio, J. J., Swank, V., Lu, H., Brunet, S., Baltan, S., Khapre, R. V., et al. (2016). Neutrophil depletion after subarachnoid hemorrhage improves memory via NMDA receptors. Brain Behav. Immun. 54, 233-242. doi: 10.1016/j.bbi.2016.02.007

Purushothaman, K. R., Purushothaman, M., Levy, A. P., Lento, P. A., Evrard, S., Kovacic, J. C., et al. (2012). Increased expression of oxidation-specific epitopes and apoptosis are associated with haptoglobin genotype: possible implications for plaque progression in human atherosclerosis. J. Am. Coll. Cardiol. 60, 112-119. doi: 10.1016/j.jacc.2012.04.011

Ramchand, P., Nyirjesy, S., Frangos, S., Doerfler, S., Nawalinski, K., Quattrone, F., et al. (2016). Thromboelastography parameter predicts outcome after subarachnoid hemorrhage: an exploratory analysis. World Neurosurg. 96, 215-221. doi: 10.1016/j.wneu.2016.04.002

Ray, W. Z., Strom, R. G., Blackburn, S. L., Ashley, W. W., Sicard, G. A., and Rich, K. M. (2009). Incidence of deep venous thrombosis after subarachnoid hemorrhage. J. Neurosurg. 110, 1010-1014. doi: 10.3171/2008.9.JNS08107

Recinos, P. F., Pradilla, G., Thai, Q. A., Perez, M., Hdeib, A. M., and Tamargo, R. J. (2006). Controlled release of lipopolysaccharide in the subarachnoid space of rabbits induces chronic vasospasm in the absence of blood. Surg. Neurol. 66, 463-469; discussion: 469. doi: 10.1016/j.surneu.2006.04.010

Rifkind, J. M., Mohanty, J. G., and Nagababu, E. (2014). The pathophysiology of extracellular hemoglobin associated with enhanced oxidative reactions. Front. Physiol. 5:500. doi: 10.3389/fphys.2014.00500

Roguin, A., Koch, W., Kastrati, A., Aronson, D., Schomig, A., and Levy, A. P. (2003). Haptoglobin genotype is predictive of major adverse cardiac events in the 1-year period after percutaneous transluminal coronary angioplasty in individuals with diabetes. Diabetes Care 26, 2628-2631. doi: $10.2337 /$ diacare.26.9.2628

Romano, J. G., Forteza, A. M., Concha, M., Koch, S., Heros, R. C., Morcos, J. J., et al. (2002). Detection of microemboli by transcranial Doppler ultrasonography in aneurysmal subarachnoid hemorrhage. Neurosurgery 50, 1026-1030; discussion: 30-31. doi: 10.1097/00006123-200205000-00016

Rosengart, A. J., Schultheiss, K. E., Tolentino, J., and Macdonald, R. L. (2007). Prognostic factors for outcome in patients with aneurysmal subarachnoid hemorrhage. Stroke 38, 2315-2321. doi: 10.1161/STROKEAHA.107.484360 
Rosi, S., Ramirez-Amaya, V., Hauss-Wegrzyniak, B., and Wenk, G. L. (2004). Chronic brain inflammation leads to a decline in hippocampal NMDA-R1 receptors. J. Neuroinflammation 1:12. doi: 10.1186/1742-2094-1-12

Sabri, M., Ai, J., Lakovic, K., D’Abbondanza, J., Ilodigwe, D., and Macdonald, R. L. (2012). Mechanisms of microthrombi formation after experimental subarachnoid hemorrhage. Neuroscience 224:26-37. doi: 10.1016/j.neuroscience.2012.08.002

Sabri, M., Ai, J., Lass, E., D’Abbondanza, J., and Macdonald, R. L. (2013a). Genetic elimination of eNOS reduces secondary complications of experimental subarachnoid hemorrhage. J. Cereb. Blood Flow Metab. 33, 1008-1014. doi: $10.1038 /$ jcbfm.2013.49

Sabri, M., Lass, E., and Macdonald, R. L. (2013b). Early brain injury: a common mechanism in subarachnoid hemorrhage and global cerebral ischemia. Stroke Res. Treat. 2013:394036. doi: 10.1155/2013/394036

Sadrzadeh, S. M., Graf, E., Panter, S. S., Hallaway, P. E., and Eaton, J. W. (1984). Hemoglobin. A biologic fenton reagent. J. Biol. Chem. 259, 14354-14356.

Sadrzadeh, S. M., Saffari, Y., and Bozorgmehr, J. (2004). Haptoglobin phenotypes in epilepsy. Clin. Chem. 50, 1095-1097. doi: 10.1373/clinchem.2003.028001

Schaer, C. A., Deuel, J. W., Bittermann, A. G., Rubio, I. G., Schoedon, G., Spahn, D. R., et al. (2013). Mechanisms of haptoglobin protection against hemoglobin peroxidation triggered endothelial damage. Cell Death Differ. 20, 1569-1579. doi: $10.1038 /$ cdd. 2013.113

Schaer, C. A., Deuel, J. W., Schildknecht, D., Mahmoudi, L., Garcia-Rubio, I., Owczarek, C., et al. (2016). Haptoglobin preserves vascular nitric oxide signaling during hemolysis. Am. J. Respir. Crit. Care Med. 193, 1111-1122. doi: $10.1164 / \mathrm{rccm} .201510-2058 \mathrm{OC}$

Schaer, D. J., Buehler, P. W., Alayash, A. I., Belcher, J. D., and Vercellotti, G. M. (2013). Hemolysis and free hemoglobin revisited: exploring hemoglobin and hemin scavengers as a novel class of therapeutic proteins. Blood 121, 1276-1284. doi: 10.1182/blood-2012-11-451229

Schaer, D. J., Vinchi, F., Ingoglia, G., Tolosano, E., and Buehler, P. W. (2014). Haptoglobin, hemopexin, and related defense pathways-basic science, clinical perspectives, and drug development. Front. Physiol. 5:415. doi: 10.3389/fphys.2014.00415

Schneider, U. C., Davids, A. M., Brandenburg, S., Müller, A., Elke, A., Magrini, S., et al. (2015). Microglia inflict delayed brain injury after subarachnoid hemorrhage. Acta Neuropathol. 130, 215-231. doi: 10.1007/s00401-015-1440-1

Schubert, G. A., Seiz, M., Hegewald, A. A., Manville, J., and Thome, C. (2011). Hypoperfusion in the acute phase of subarachnoid hemorrhage. Acta Neurochir. Suppl. 110(Pt 1), 35-38. doi: 10.1007/978-3-7091-0353-1_6

Sehba, F. A., Hou, J., Pluta, R. M., and Zhang, J. H. (2012). The importance of early brain injury after subarachnoid hemorrhage. Prog. Neurobiol. 97, 14-37. doi: 10.1016/j.pneurobio.2012.02.003

Sehba, F. A., Mostafa, G., Friedrich, V. Jr., and Bederson, J. B. (2005). Acute microvascular platelet aggregation after subarachnoid hemorrhage. J. Neurosurg. 102, 1094-1100. doi: 10.3171/jns.2005.102.6.1094

Sehba, F. A., Mostafa, G., Knopman, J., Friedrich, V. Jr., and Bederson, J. B. (2004). Acute alterations in microvascular basal lamina after subarachnoid hemorrhage. J. Neurosurg. 101, 633-640. doi: 10.3171/jns.2004.101.4.0633

Sehba, F. A., Schwartz, A. Y., Chereshnev, I., and Bederson, J. B. (2000). Acute decrease in cerebral nitric oxide levels after subarachnoid hemorrhage. J. Cereb. Blood Flow Metab. 20, 604-611. doi: 10.1097/00004647-200003000-00018

Sertório, J. T., Lacchini, R., Amaral, L. M., Palei, A. C., Cavalli, R. C., Sandrim, V. C., et al. (2013). Haptoglobin polymorphism affects nitric oxide bioavailability in preeclampsia. J. Hum. Hypertens. 27, 349-354. doi: 10.1038/jhh.2012.57

Shi, P. A., Choi, E., Chintagari, N. R., Nguyen, J., Guo, X., Yazdanbakhsh, K., et al. (2016). Sustained treatment of sickle cell mice with haptoglobin increases HO- 1 and $\mathrm{H}$-ferritin expression and decreases iron deposition in the kidney without improvement in kidney function. Br. J. Haematol. 175, 714-723. doi: 10.1111/bjh.14280

Shigeno, T., Fritschka, E., Brock, M., Schramm, J., Shigeno, S., and CervośNavarro, J. (1982). Cerebral edema following experimental subarachnoid hemorrhage. Stroke 13, 368-379. doi: 10.1161/01.STR.13.3.368

Shikama, K. (1998). The molecular mechanism of autoxidation for myoglobin and hemoglobin: a venerable puzzle. Chem. Rev. 98, 1357-1374. doi: 10.1021/cr970042e

Siironen, J., Juvela, S., Varis, J., Porras, M., Poussa, K., Ilveskero, S., et al. (2003). No effect of enoxaparin on outcome of aneurysmal subarachnoid hemorrhage: a randomized, double-blind, placebo-controlled clinical trial. J. Neurosurg. 99, 953-959. doi: 10.3171/jns.2003.99.6.0953

Silva, G., Jeney, V., Chora, A., Larsen, R., Balla, J., and Soares, M. P. (2009). Oxidized hemoglobin is an endogenous proinflammatory agonist that targets vascular endothelial cells. J. Biol. Chem. 284, 29582-29595. doi: 10.1074/jbc.M109.045344

Simard, J. M., Aldrich, E. F., Schreibman, D., James, R. F., Polifka, A., and Beaty, N. (2013). Low-dose intravenous heparin infusion in patients with aneurysmal subarachnoid hemorrhage: a preliminary assessment. J. Neurosurg. 119, 1611-1619. doi: 10.3171/2013.8.JNS1337

Soares, M. P., and Hamza, I. (2016). Macrophages and iron metabolism. Immunity 44, 492-504. doi: 10.1016/j.immuni.2016.02.016

Stegmayr, B., Eriksson, M., and Asplund, K. (2004). Declining mortality from subarachnoid hemorrhage: changes in incidence and case fatality from 1985 through 2000. Stroke 35, 2059-2063. doi: 10.1161/01.STR.0000138451.07853.b6

Stein, S. C., Browne, K. D., Chen, X. H., Smith, D. H., and Graham, D. I. (2006). Thromboembolism and delayed cerebral ischemia after subarachnoid hemorrhage: an autopsy study. Neurosurgery 59, 781-787; discussion: 7-8. doi: 10.1227/01.NEU.0000227519.27569.45

Sun, B. L., Zhang, S. M., Xia, Z. L., Yang, M. F., Yuan, H., Zhang, J., et al. (2003). L-arginine improves cerebral blood perfusion and vasomotion of microvessels following subarachnoid hemorrhage in rats. Clin. Hemorheol. Microcirc. 29, 391-400.

Sun, J., Feng, A., Zhang, Y., Sun, S., Hu, W., Yang, M., et al. (2010). Fucoidan increases TNF-alpha-induced MMP-9 secretion in monocytic cell line U937. Inflamm. Res. 59, 271-276. doi: 10.1007/s00011-009-0095-6

Suzuki, H., Hasegawa, Y., Chen, W., Kanamaru, K., and Zhang, J. H. (2010). Recombinant osteopontin in cerebral vasospasm after subarachnoid hemorrhage. Ann. Neurol. 68, 650-660. doi: 10.1002/ana.22102

Suzuki, S., Kimura, M., Souma, M., Ohkima, H., Shimizu, T., and Iwabuchi, T. (1990). Cerebral microthrombosis in symptomatic cerebral vasospasm-a quantitative histological study in autopsy cases. Neurol. Med. Chir. 30, 309-316. doi: 10.2176/nmc.30.309

Terry, C. M., Clikeman, J. A., Hoidal, J. R., and Callahan, K. S. (1998). Effect of tumor necrosis factor-alpha and interleukin-1 alpha on heme oxygenase-1 expression in human endothelial cells. Am. J. Physiol. 274(3 Pt 2), H883-H891.

Thomsen, J. H., Etzerodt, A., Svendsen, P., and Moestrup, S. K. (2013). The haptoglobin-CD163-heme oxygenase-1 pathway for hemoglobin scavenging. Oxid. Med. Cell. Longev. 2013:523652. doi: 10.1155/2013/523652

Tobinick, E. (2009). Tumour necrosis factor modulation for treatment of Alzheimer's disease: rationale and current evidence. CNS Drugs 23, 713-725. doi: 10.2165/11310810-000000000-00000

Touyz, R. M., and Schiffrin, E. L. (2004). Reactive oxygen species in vascular biology: implications in hypertension. Histochem. Cell Biol. 122, 339-352. doi: 10.1007/s00418-004-0696-7

Trojanowski, T. (1982). Blood-brain barrier changes after experimental subarachnoid haemorrhage. Acta Neurochir. 60, 45-54. doi: 10.1007/BF01401749

Ueno, M. (2007). Molecular anatomy of the brain endothelial barrier: an overview of the distributional features. Curr. Med. Chem. 14, 1199-1206. doi: 10.2174/092986707780597943

Vallelian, F., Pimenova, T., Pereira, C. P., Abraham, B., Mikolajczyk, M. G., Schoedon, G., et al. (2008). The reaction of hydrogen peroxide with hemoglobin induces extensive alpha-globin crosslinking and impairs the interaction of hemoglobin with endogenous scavenger pathways. Free Radic. Biol. Med. 45, 1150-1158. doi: 10.1016/j.freeradbiomed.2008.07.013

Valone, F. H., and Epstein, L. B. (1988). Biphasic platelet-activating factor synthesis by human monocytes stimulated with IL-1-beta, tumor necrosis factor, or IFN-gamma. J. Immunol. 141, 3945-3950.

van den Bergh, W. M., Group, M. S., Algra, A., Dorhout Mees, S. M., van Kooten, F., Dirven, C. M., et al. (2006). Randomized controlled trial of acetylsalicylic acid in aneurysmal subarachnoid hemorrhage: the MASH Study. Stroke 37, 2326-2330. doi: 10.1161/01.STR.0000236841.16055.0f

Vecchione, C., Frati, A., Di Pardo, A., Cifelli, G., Carnevale, D., Gentile, M. T., et al. (2009). Tumor necrosis factor-alpha mediates hemolysis-induced vasoconstriction and the cerebral vasospasm evoked by subarachnoid hemorrhage. Hypertension 54, 150-156. doi: 10.1161/HYPERTENSIONAHA.108.128124 
Vergouwen, M. D., Vermeulen, M., Coert, B. A., Stroes, E. S., and Roos, Y. B. (2008). Microthrombosis after aneurysmal subarachnoid hemorrhage: an additional explanation for delayed cerebral ischemia. J. Cereb. Blood Flow Metab. 28, 1761-1770. doi: 10.1038/jcbfm.2008.74

Vinchi, F., Costa da Silva, M., Ingoglia, G., Petrillo, S., Brinkman, N., Zuercher, A., et al. (2016). Hemopexin therapy reverts heme-induced proinflammatory phenotypic switching of macrophages in a mouse model of sickle cell disease. Blood 127, 473-486. doi: 10.1182/blood-2015-08663245

Voetsch, B., Jin, R. C., and Loscalzo, J. (2004). Nitric oxide insufficiency and atherothrombosis. Histochem. Cell Biol. 122, 353-367. doi: 10.1007/s00418-004-0675-z

Vormittag, R., Vukovich, T., Mannhalter, C., Minar, E., Schönauer, V., Bialonczyk, C., et al. (2005). Haptoglobin phenotype 2-2 as a potentially new risk factor for spontaneous venous thromboembolism. Haematologica 90, 1557-1561.

Wagner, D. D., and Burger, P. C. (2003). Platelets in inflammation and thrombosis. Arterioscler. Thromb. Vasc. Biol. 23, 2131-2137. doi: 10.1161/01.ATV.0000095974.95122.EC

Wintrobe, M. M., and Greer, J. P. (2004). Wintrobe's Clinical Hematology, 11th Edn. Philadelphia, PA: Lippincott Williams \& Wilkins.

Woitzik, J., Dreier, J. P., Hecht, N., Fiss, I., Sandow, N., Major, S., et al. group Cs. (2012). Delayed cerebral ischemia and spreading depolarization in absence of angiographic vasospasm after subarachnoid hemorrhage. J. Cereb. Blood Flow Metab. 32, 203-212. doi: 10.1038/jcbfm.2011.169

Xi, G., Keep, R. F., and Hoff, J. T. (1998). Erythrocytes and delayed brain edema formation following intracerebral hemorrhage in rats. J. Neurosurg. 89, 991-996. doi: 10.3171/jns.1998.89.6.0991
Yamamoto, K., Shimokawa, T., Kojima, T., Loskutoff, D. J., and Saito, H. (1999) Regulation of murine protein $\mathrm{C}$ gene expression in vivo: effects of tumor necrosis factor-alpha, interleukin-1, and transforming growth factor-beta. Thromb. Haemost. 82, 1297-1301. doi: 10.1055/s-0037-1614379

Zacharia, B. E., Hickman, Z. L., Grobelny, B. T., DeRosa, P., Kotchetkov, I., Ducruet, A. F., et al. (2010). Epidemiology of aneurysmal subarachnoid hemorrhage. Neurosurg. Clin. N. Am. 21, 221-233. doi: 10.1016/j.nec.2009.10.002

Zhao, X., Song, S., Sun, G., Strong, R., Zhang, J., Grotta, J. C., et al. (2009). Neuroprotective role of haptoglobin after intracerebral hemorrhage. J. Neurosci. 29, 15819-15827. doi: 10.1523/JNEUROSCI.3776-09.2009

Zhao, X., Sun, G., Zhang, J., Strong, R., Dash, P. K., Kan, Y. W., et al. (2007). Transcription factor Nrf2 protects the brain from damage produced by intracerebral hemorrhage. Stroke 38, 3280-3286. doi: 10.1161/STROKEAHA.107.486506

Conflict of Interest Statement: The authors declare that the research was conducted in the absence of any commercial or financial relationships that could be construed as a potential conflict of interest.

Copyright (c) 2018 Blackburn, Kumar, McBride, Zeineddine, Leclerc, Choi, Dash, Grotta, Aronowski, Cardenas and Doré. This is an open-access article distributed under the terms of the Creative Commons Attribution License (CC BY). The use, distribution or reproduction in other forums is permitted, provided the original author(s) and the copyright owner are credited and that the original publication in this journal is cited, in accordance with accepted academic practice. No use, distribution or reproduction is permitted which does not comply with these terms. 